\title{
Ethical dilemmas for researchers working in international contexts
}

\author{
Ray Doiron, PhD \\ University of Prince Edward Island, Canada \\ Marlene Asselin, PhD \\ University of British Columbia, Canada
}

Keywords: Ethics, Researchers, International contexts

\section{Introduction}

The International Association for School Librarianship (IASL) has a reputation for supporting and disseminating research informing school librarianship around the world. Since the organization serves a multi-national and multi-cultural library community, it has the responsibility to promote sound ethical procedures for all research. This can raise serious dilemmas for researchers planning to work in Global South countries with few or different ethical standards for conducting research when, as members of the Global North academic community, we are bound by strict guidelines covering ethical procedures. These dilemmas can include: 1) differing views on what counts as research: 2) differing values and policies on gender, religion, inclusive practices and other social and cultural areas; 3) the insider/outsider phenomenon (white privileged researchers working in non-white communities; and 4) developing research instruments that are culturally sensitive. These dilemmas present serious challenges as we set out to conduct research in school and community libraries in remote/rural areas and large urban centers where frontline staff have little or no experience with, nor knowledge of, educational research. Researchers are charged then to pay serious attention to issues of positionality, paradigms of what is "truth", iterative methods and analyses, as well as an overarching awareness of their reflexivity throughout the research process. Research in this context becomes a continuous process of examining our relationship with fellow researchers and research participants, the dynamics of that relationship, and its relationship to the research that is undertaken. Without a self-critical lens through which we engage in the research process we run the risk of placing ourselves in the position where "ethical research guidelines \{as imposed by Universities\} could be yet another western construct that create a global discourse of 'our way' is the 'right way' to do things" (Skelton, 2008, p. 29).

Over the past two decades, the ethics of research involving children and youth has become a prominent topic in the literature (Powell, Fitzgerald, Taylor, \& Graham, 2012), sparking a proliferation of resources for researchers (Alderson \& Morrow, 2011; Childwatch International Research Network, n.d.; Graham, Powell, Taylor, Anderson \& Fitzgerald, 2013; Young Lives, n.d.; UNICEF Office of Research, n.d). Spurred by the UN Convention on the Rights of the Child (1989) and the emergence of the sociology of childhood (Mayall, 2002), accordant rights-protecting procedures were instituted and methods of research designed to enable 
voices of children and youth to be heard to various degrees throughout the research process. However, from an international perspective, this paradigm of research with children and the knowledge generated by it are unbalanced since ... 'only a little more than $10 \%$ of the world's children live in the developed countries of Europe, North America and other European outposts... yet the research is heavily concentrated on children from these places" (Pence \& Nsamenang, 2008, p.14).

How then should researchers working with children in school and community libraries develop research that assures fair and respectful ethical procedures? What role do children play in the research process - subject, informant or participant? How can Western researchers approach research in developing countries where expectations for ethical research may or may not exist? This paper takes a critical perspective on these issues by: 1) reflecting on the various stances that researchers take in approaching new research;2) comparing expectations for ethics in developed and developing countries; and 3) identifying the position children are placed in before, during and after research projects. We begin our discussion by examining some of the current political, economic and ethical challenges facing researchers wishing to work in international contexts.

\section{Research Challenges}

All research is influenced by the political climate in which it is generated and then conducted. In Canada, we see several examples of what could be called 'political interference' when we see major research organizations issue calls for proposals usually framed within specified themes, such as gender issues, aboriginal culture or adult/workplace literacy. Often these themes come with expectations that partnerships and collaborations will be developed; outcomes and deliverables will be achieved; and some economic impact will accrue from the research. This becomes a pressure for 'real' results and 'real world' applications that can stifle some forms of research and leave researchers chasing projects that meet the criteria of the themes outlined by the governing research bodies. Similarly university research offices frame their research directions within the same thematic frameworks and review proposals with key national criteria in place.

In international contexts, political and economic pressures are also exerted on researchers, non-governmental agencies, as well as government departments of education and health. Many African countries for example are currently being supported by large international aid organizations e.g., (US AID, British Council, Australia AID) who bring new energy, reform and money to help emerging economy countries meet Millennial Development Goals (MDG) and achieve "literacy for all'. These initiatives are also closely monitored through large-scale assessments and mostly quantitative program evaluations. Since with in-country researchers have limited research experiences, these major 'outside' initiatives dominate the research landscape. In similar ways, local governments set their educational priorities with many countries emphasizing secondary and post-secondary initiatives that see new universities and colleagues being established and priority being given to science and technology programs. 


\section{Funding Challenges}

Tied closely to the political agendas of governments, foundations, donor and international aid agencies are issues related to research funding. It takes financial resources to be able to develop research projects and in the Canadian context, funding sources are closely tied to the political and long-range goals outlined by these organizations. A 'corporate' model has emerged with funders expecting results that will further their agendas. Most universities and colleges in Canada have clear statements outlining the research foci that will be supported collaborative, interdisciplinary, marginalized groups with increasing expectations for researchers to be finding international partners for their projects. It would be fair to say that without attention to these criteria, a researcher would likely not get funded.

Most universities in Canada have also developed large research offices with a growing staff for managing and leading research in each faculty, searching for new funding sources, supporting grant writing, and leading efforts at research dissemination. Strategic vision statements have been written in most institutions and these documents guide the types of funding grants that will be supported.

In the international context, the links between political agendas and research funding are just as obvious. With most of the funding for major literacy initiatives coming from outside the country (such as from international aid, donor and faith-based organizations), researchers in many African countries are attracted to these funding sources. With little or no internal research funding and many university-based researchers largely self-funded, their research remains isolated from their continental and global colleagues and lacking in a cohesive strategy over the long term. Adding to the difficulties facing these researchers, there are even less funds available for research dissemination or travel for conferences in most developing countries. The rise of open access journals has started to have some impact on getting the research in these countries more accessible to the world.

\section{Ethical Challenges}

Most universities in the Global North are advocating for researchers to develop international research projects by forming university-to-university academic agreements that include program sharing, faculty and student exchanges and research collaborations which also increases the challenges for matching ethical standards between the two (or more) institutions. In Canada the United Nations Charter of Rights for the Child and the Canadian Charter of Rights and Freedom dominate the contexts in which all research must be done. The Canadian government through its Tri-Council agencies sets policies, guidelines and procedures for conducting research internally within the country (with additional guidelines for marginalized individuals and communities) and gives special attention to international research (See Tri-Council Policy Statement of Research with Humans). Local universities and colleges take the Tri-Council directives and guide their implementation through their own in-house research policies/procedures led by Research Ethics Boards (REBs) established at each post-secondary institution. All of these regulations affect the research context in Canada and must be addressed faithfully in order to receive and maintain research funding. These regulations cover such issues as the privacy and safety of research participants, gaining access to populations, the use of tape recorders, cameras and video, Internet access, and informed consent/assent to name a few. Researchers are advised to follow regulations for involving community members in the research, make plans for on-going communication with participants, as well as plans for reporting back to participants as part of 
their dissemination plans. All of these regulations are even more stringent when researchers are working with vulnerable populations in the country.

In the international context, few countries of the Global South have instituted comprehensive processes for conducting educational research. In many cases with educational research, no formal ethical approval is needed. Researchers (often a male authority figure) enter a school assuming children and teachers will participate in whatever projects they are undertaking. Parents are rarely asked for permission to involve their children and children are not asked to give assent to take part. In addition, there is little reporting back to participants once results have been analyzed.

\section{Dilemmas Arising}

With this brief look at the political, economic and ethical challenges facing researchers in Canada and some developing countries, we turn now to examine some of the dilemmas arising out of these challenges. The dilemmas can be briefly stated in this way:

- Differing views of what counts as research. Within our country and beyond its borders, researchers are faced with meeting the needs of those who expect research to be quantitative in design yielding results that "prove" what works and those who expect research to be more qualitative giving a richer and more robust sense of a phenomenon and those affected by it.

- The qualitative/quantitative dilemma is particularly prevalent as the Global North view of research meets the emerging research culture in countries like Ethiopia, Kenya, Uganda and other developing countries in Africa. In these countries the quantitative research culture is deeply entrenched while increasing numbers of 'outside' researchers view research from a socio-cultural, more qualitative perspective thus immediately running into competing "worldviews".

- Role of the child in the research. As we work internationally we also see variance in the position of the child in the research process. There is a range of views of the child from simply being a passive subject acted upon through to being a competent participant in the research with important perceptions on matters that affect their lives (Asselin \& Doiron, submitted). Do we provide children with the opportunity to give informed consent or at least assent?

- Insiders and outsiders. The majority of Western researchers are white, privileged academics who are attempting to move into very different cultural situations than their own. These are not only cultural differences such as food, dress, religion and language but differences in previous research experiences, access to a wealth of resources unknown to many emerging researchers in developing countries, and often with expectations that English will be the dominant language used for any partnership and collaborations.

- Differing inclusive policies and practices. In Canada we are governed by strict policies and common beliefs/values about diversity, equity and inclusion. These values extend into all vulnerable communities, differences in gender roles, religions, sexual orientation, and the myriad of developmental and physical limitations common in any society. However, such policies and practices around inclusion are just emerging in many developing countries and there are underlying differences in how people perceive gender roles, diverse religions and equal rights for all.

- Western requirements for ethical procedures. How do we proceed and what are we to do with data collected outside of the standards established by our national agencies 
and our local university REBs? Can we analyze and then disseminate findings if the data was not collected following our national procedures? Are participants in research truly giving informed consent or merely going along with authority figures? The data collection process may seem appropriate and 'legal' in the local context but would likely be disqualified without following the ethical standards established by our parent institutions.

- Developing/adapting culturally sensitive instruments culturally sensitive. Coupled with issues of the ethical collection of data are ones related to the construction of data tools that are culturally sensitive, reflective of how 'locals' would address the issues and written in a language that is accessible to all participants. We are often in the situation where we are developing instruments in our first language (usually English) when this may be the second or even third language of local users of such an instrument. How we say things in English may not be easily translated into Amharic, Tswahili or Luganda for example.

\section{Research 'Headwork'}

Faced with these challenges and ethical dilemmas, researchers wishing to work with colleagues in developing countries need to approach their research with a new set of lenses through which they initiate, conduct, analyze and report research in these international contexts. Sultana (2006) emphasizes that "fieldwork is always contextual, relational, embodied, and political (p.374)". What emerges then is a complex iterative research process that folds back into itself repeatedly relying on deep listening, ongoing communication, reflection, re-visioning and attention to ethics in both the originating context and the local situation where the work will be done. Thus, library researchers need to become less reliant on traditional data collection and analysis methods to develop a more generative, iterative, conceptual process more focused on building research capacity and new understandings of educational research. All of this should be developing with the ever-present trepidation about imposing values and shades of post-colonialism on the people and contexts in which we hope to work.

On the other hand, if we stop and think about it, these dilemmas could provide us with a rich space in which to build our collaborations around exploring mutual issues, finding common ground and focusing on what Chiseri-Strater and Sunstein (2006) call the "headwork" in doing research. This headwork involves critical "habits of mind", such as: a) The 'nature of truth'; b) reflexivity; c) positionality; 4) emergent methods, analysis and findings; and 5) dissemination. We will take a brief look at each one.

\section{The 'nature of truth'}

Competing paradigms for research as exemplified by the qualitative/quantitative debate really represent differing epistemologies and a concern with the nature and scope of knowledge. One spectrum of research approach is based on the notion that 'truth' is simply 'out there' and we just have to discover it, while the other assumes that all meanings are interactively and socially constructed. Most researchers see benefits in both approaches but tend philosophically to lean to one or the other. How we see the world and how we understand the purposes and processes for doing research, and how we understand how we form new knowledge are all factors in determining what we see as the 'truth'. When attempting to develop research with new colleagues, researchers need to be cognizant that 
they may be coming from a different paradigm and that a negotiation needs to take place to ensure each worldview is recognized, respected and employed to achieve a balance in the relationship.

In our past experiences with school library research, we have learned that non-pragmatic research (such as ethnography, hermeneutics, narrative and other socio-cultural approaches) holds little resonance with politicians and decision-makers. This has forced us to more clearly articulate the goals, the value and the impact of our research. This is understandable given the need for impact in countries faced with extreme challenges in health and education brought on by poverty and slow economic growth.

\section{Reflexivity}

Reflexivity involves making the research process itself a focus of inquiry where researchers lay open pre-conceptions to become aware of situational dynamics and to recognize that all participants are jointly involved in knowledge production. Research then becomes a continuous process of examining our "personal baggage" (Kirby \& McKenna, 1989) and personal assumptions, our preconceptions and how they affect all research decisions. When we work with other colleagues we enter into a continuous process examining our relationship, the dynamics of that relationship and its impact on the research.

As we move into research in school and community libraries in global communities, we must be very aware that our vision for how a school library operates may be vastly different than our colleagues in small, under-developed libraries. Our experiences working in such libraries has taught us that while the quantity and quality of resources is wanting, and the training and sophistication of library program is still emerging, the very essence of what a library is and how it contributes to learning and the culture for reading in a community is very strong in all of these libraries.

\section{Positionality}

All researchers are positioned by factors of age, gender, race, class, nationality, religion, institutional affiliation, historical and personal circumstances and intellectual disposition. The extent to which such influences are revealed or concealed is circumscribed by the paradigms and disciplines under which we train, work, and publish.

Recognizing our position and using it as a lens through which we do our research will shed light on: 1) the power relations that would affect the kinds of relations we have with the people we work with, and therefore the kinds of information we observe; and 2) the effect of our own subjectivity might have on how we interpret "results" (Chiseri-Strater, n.d.; Kapoor, 2004; Ganga \& Scott, 2006).

As we began our work with libraries in Ethiopia we felt very much like O'Leary (n.d.) who expresses her reflections about the position she experienced.

At the outset of a research or consulting project, my social identification by others as an outsider and an 'expert' has generally meant that I have been invested with power by others in the group. Yet the philosophy that underpins my worldview and the ways in which I engage in research is a collaborative and participative one which is based on sharing power (p.2). 
This means that as researchers we need to take the time to listen, to engage respectfully with our counterparts and take small steps towards a mutual position regarding what questions we will explore, how we will explore them and what we ultimately will do with any results we may attain.

\section{Emergent methods, analyses and findings}

Jones (2006) warns researchers that "the processes of coding, analysis, interpretation and reporting of data can be colored by the researcher's conceptual framework to the exclusion of the informants, placing the researcher in a supreme position of control over the research process (p.171)". This forces us to re-examine the traditional research model where questions are generated, data is collected, analysis is completed away from the informants and findings are reported in isolation. The entire process must become an iterative one where the research team develops the research focus that becomes a starting point for the study. Research tools are adapted, revised, and responsive to the context and the feedback from participants. Findings emerge throughout the process and not simply at the end. Participants verify and add input to the analysis helping to keep the richness of the situation. In other words, context and socio-cultural factors influence the development of research methods and analysis.

Our experiences with a family literacy program led by community library staff brought home many of these issues as we set out to adapt a literacy assessment instrument to the languages, cultural contexts and informed consent procedures most of which were nonexistent. Our partners in the work were unfamiliar with such instruments and worked along with us to translate the questions not only into local languages but also in recognizable situations familiar to those who would do the assessment.

\section{Dissemination}

In a traditional research model, researchers wait until their data has been collected, analyzed and a set of findings is developed. Too often, Western researchers share their work in journals and conference venues where global perspectives and participants may be limited. In a reflexive model, dissemination is seen as part of the on-going collaborative, participatory process where one cycle of collaborative work leads into the next, where established relationships can grow and deepen as respect is building and collaborators trust each other more easily. It is not seen as a 'take the data and run' process. This has led to Western researchers looking for 'new venues' to share research results, ones that are closer to the global community where the work took place. In addition, it has led to opportunities to facilitate local researchers getting their work shared at in-country and international conferences (See CIES at http://www.cies.us for example) and having articles published in peer-reviewed journals (See the IFLA Journal and School Libraries Worldwide for examples).

\section{Research 'Alerts'}

We are familiar with the concept of 'alerts', those messages (sometimes annoying) we receive alerting us to some new ideas, resources or innovations. An alert is also seen as a warning, a 'heads-up' about potential problems or issues you need to be aware of before venturing out on a new project in the hopes of avoiding them or preventing them from happening. We need to be on the alert for situations, ideologies and new understandings that will challenge what we have been doing traditionally in our research while leading us to new research landscapes where true collaboration and meaningful new insights into school and 
community library effectiveness can be identified and disseminated in a global and democratic exchange of ideas. Taking a more critical approach to research will be challenging and will increase the time it takes to get a research agenda established, one based on mutual respect, true collaboration and mutual benefit. With this vision in place, we offer several research 'alerts' that colleagues need to be aware of and prepared to accept.

1) As more Western academics move into research partnerships with nongovernmental organizations, university collaborators and frontline library leaders, they need to embrace a more critical research paradigm where research is understood as "the co-production of new understandings and solutions that tap the expertise of non-academic partners." (Sharrock, 2007, p. 10).

2) Skelton (2008) warns us that "ethical research guidelines as imposed by Universities\} could be yet another Western construct that creates a global discourse of 'our way' is the 'right way' to do things" (p. 29).

3) The lack of regulatory mechanisms in some Majority world contexts, places the onus on researchers and the institutions to which they belong (Leach, 2006). Part of our role is to help local researchers develop the ethical principles that will enhance their research and ensure participants of fair and respectful treatment.

4) Ethical codes that are restrictive and binding need to become more iterative and responsive, which does not fit the standard format of knowing in advance what will happen and how it will be managed, as is generally required by ethics boards in Western universities and colleges.

5) Be knowledgeable of local policies concerning education and research. For example, although the UN Convention of the Rights of the Child may be supposed universal, Africa has its own Charter of the Rights and Welfare of the Child (http://www.au.int/en/sites/default/files/Charter En African Charter on the Rights and Wlefare of the Child AddisAbaba July1990.pdf).

\section{A Challenge for IASL in Moving Forward}

Many professional associations including the International Association of School Librarianship (IASL) originated in Western countries. The IASL has worked diligently to build international membership and encourage school library development globally. This has included disseminating current research at its annual conference, research grants and publications in School Libraries Worldwide. However, as research and collaborations are encouraged by government, funders and the Academy to become more global, the persistent dominance of Western perspectives is uncomfortable for present and future members. In IASL, by far the majority of research remains carried out and published by colleagues in Western countries (Asselin, 2011). Are we doing enough to support and disseminate school library research being conducted by the global school library community? Is some of that research being done but not reaching an international audience? How can IASL show leadership in gathering and disseminating that research? As we move into more global partnerships around research, could IASL offer guidelines for conducting that research in ethical and respectful ways?

In Canada as in all Western countries, institutions and organizations are composing visions, guidelines and principles for the current reality of being a researcher in an international arena (Association of Canadian Deans of Education, 2014; Canadian Bureau for International Education; 2013; Ethics of International Engagement and Service-Learning Project, 2011). The potential of principled, collaborative, international research includes "increased 
intercultural understanding and dialogue through a realization of interdependence" . . and "building partnerships based on reciprocity, social accountability, and sustainability" (Association of Canadian Deans of Education, 2014, p. 5). From such potential, enormous opportunities for supporting economic and social justice are afforded.

Internationalization offers an opportunity to establish collaborative, ethical partnerships that foster the ideals of economic and social justice and that take us beyond the ethnocentric, hegemonic, depoliticized, and paternalistic historical patterns of engagement. In turn, increased understanding may result in a reciprocal improvement of educational research and practices. (Association of Canadian Deans of Education, 2014, p. 5).

As an international association representing libraries supporting teaching and learning for children and youth throughout the world, IASL needs to seriously take renewed responsibility to ensure ethical research for their global membership and for the larger library community. In this paper, we have identified key issues and challenges, have provided concepts that can undergird formation of ethical international research, and pointed to exemplary documents by relevant institutions and associations. It is time for IASL to step forward for the global school library community.

\section{References}

Alderson P., \& Morrow V. (2011). The ethics of research with children and young people: A practical handbook. London: Sage Publications.

Asselin, M. (2011). Internationalism as leadership in IASL research: Accomplishments and directions. School Libraries Worldwide, 17(2), 13-24.

Asselin, M., \& Doiron, R. (submitted). Toward an ethical research praxis in literacy research with young children in the Majority World. Canadian and International Education Journal.

Association of Canadian Deans of Education (2014). Accord on the Internationalization of Education. Available at: http://www.csse-scee.ca/docs/acde/Accord Internationalization EN.pdf

Canadian Bureau for International Education. (2013). Code of Ethical Practice of the Canadian Bureau for International Education (CIBE). Available at: http://www.cbie.ca/members/code-of-ethical-practice/

Childwatch Research Network. (n.d.). Available at: http://www.childwatch.uio.no/

Chiseri-Strater, E., \& Sunstein, B. S. (2006). What works?: A practical guide for teacher research. Portsmouth, $\mathrm{NH}$ : Heinemann.

Chsieri-Strater, E. (n.d.). Turning in upon ourselves: Positionality, subjectivity and 
reflexivity in case studies and ethnographic research. Available at:

http://joemoxley.org/sites/Joe Moxley/research/AssignedReadings/Jennie\%20Dau

terman,\%20Social\%20and\%20Institutional\%20Power\%20Relationships.pdf

Ethics of International Engagement and Service-Learning Project. (2011). Global praxis:

Exploring the ethics of engagement abroad. Vancouver, BC. Available at:

http://ethicsofisl.ubc.ca

Ganga, D., \& Scott, S. (2006). Cultural "Insiders" and the issue of positionality in qualitative migration research: Moving "across" and moving "along" researcherparticipant divides. Forum Qualitative Sozialforschung / Forum: Qualitative Social Research, 7(3), Art. 7. Available at: http://nbn-resolving.de/urn:nbn:de:0114-fqs060379

Graham, A., Powell, M., Taylor, N., Anderson, D., \& Fitzgerald, R. (2013). Ethical research involving children. Florence: UNICEF Office of Research - Innocenti. Available at: http://childethics.com/

Jones, M. (2006). The guest from England: Exploring issues of positionality in a foreign and yet familiar setting. European Societies, 8(1), 169-187.

Kapooor, I. (2004). Hyper-self-reflexive development: Spivak on representing the Third World 'other'. Third World Quarterly, 25(4), 627-647.

Kirby, S., \& McKenna, K. (1989). Methods from the margins: Experience, Research, Social Change. Toronto, ON: Garamond Press.

Leach, F. (2006). Researching gender violence in schools: Methodological and ethical considerations. World Development, 34, 1129-1147.

Mayall, B. (2002). Towards a Sociology for Childhood: Thinking from Children's Lives. London: Open University Press.

O'Leary, D. (n.d.). Outsider positioning in action research: Struggling with being on the outside looking in. Available at: http://www.arcolloquium.weebly.com/uploads/6/9/2/5/.../doleary abstract.pdf

Pence, A., \& Nsamenang, B. (2008) A case for early childhood development in sub-Saharan Africa. Working Paper No. 51. The Hague, The Netherlands: Bernard van Leer Foundation. Available at: http://www.web.uvic.ca/ eyrd/pubs/Pence Nsamenang BvL WP 51 2008.pdf

Powell, M.A., Fitzgerald, R.M., Taylor, N., \& Graham, A (2012). International literature review: Ethical issues in undertaking research with children and young people, for the Childwatch International Research Network, Southern Cross University, Centre for Children and Young People, Lismore NSW and University of Otago, Centre for Research on Children and Families, Dunedin, NZ. 
Sharrock, G. (2007) After Copernicus: Beyond the crisis in Australian universities. Australian Universities Review, 49 (1\&2), 2-4. Available at:

http://files.eric.ed.gov/fulltext/EJ802269.pdf

Skelton, T. (2008). Research with children and young people: Exploring the tensions between ethics, competence and participation. Children's Geographies, 6 (1), $21-$ 36.

Sultana, F. (2006). Reflexivity, positionality and participatory ethics: Negotiating fieldwork dilemmas in international research. ACME: An International E-Journal for Critical Geographies, 6(3) 374-378).

Tri-Council document: Tri-Council Policy Statement of Research with Humans Chapter 9 on aboriginal and international ethical guidelines, p. 105-135. http://www.pre.ethics.gc.ca/pdf/eng/tcps2/TCPS 2 FINAL Web.pdf

UNICEF Office of Research. (n.d.). Available at: http://www.unicef-irc.org/office/

Young Lives Project (n.d.) Available at: http://www.younglives.org.uk/ 